DOI: $\underline{10.15679 / b j w r . v 2 i 1.21}$

\title{
POPULATION FLUCTUATION OF STOAT (MUSTELA ERMINEA L., 1758) IN TRANSBAIKAL REGION (RUSSIA)
}

\author{
Agafonov G., ${ }^{1}$ Erdakov L. ${ }^{2}$
}

\begin{abstract}
Summary: Population dynamics of stoat has been studied for a long time. Cyclicality of this dynamics with periods of 2-11 years in different parts of species range is registered. We analyzed data on acquisition of stoat furs in 14 districts of Transbaikal region for the period of 19 years (1971-89). We assumed that this data generally reflects long-term abundance dynamics of stoat in hunting area. Analysis of population dynamic of stoat basing on the acquisitions of furs in different districts of Transbaikalia allowed us to identify the fact that complex curves of acquisition dynamics are superposition of different cycles, which are distinct in period and power. With the employment of time-series analysis, which is graphically depicted as chronograms of abundance dynamics in different districts, we constructed distinctive figures of rhythm spectra and conducted visual comparison of this figures for different districts. We divided all districts into three groups according to the form of spectrum of abundance cycles. The first group mainly includes low frequency rhythms (12-22 years), in the second group these rhythms are totally absent. The third group of spectra is intermediate; it includes rhythms in all frequency bands which are specific for this species. High frequency rhythms are indicative for the majority of spectra, and about 4 years cycles are indicated in all spectra without any exclusion. For the first time description for low frequency cycles (16-26 years) are given. It seems that the most probably the spectrum of 6-8 visible periodicities is specific for stoat, but only part of these periodicities appear in each region. Full spectrum of rhythms of stoat, probably, will be displayed using longer-term records.
\end{abstract}

Key words: stoat, population fluctuation, rhythms, spectral analysis.

\section{Introduction}

Population dynamics of stoat has been studied for a long time. Cyclicity of such dynamics was marked at the very beginning of these studies. Thus, Formozov (1935) argued that population abundance of stoat experience fluctuations within the period of 2-3 years. Studies conducted in European North of Russia detected 3 and 8 years cycles and even 11 years periodicity (Semenov, 1976). Also similar by period, 5-9 years fluctuations of population abundance were described for the same species (Kolosov at al., 1979). There is also data on dynamics of population abundance cyclicality from Yakutia, where the length of cycles is 6-7 years (Tavrovskiy et al., 1971). Encyclopedia of wild animals of Urals (Encyclopedia, 2014) provides information on regular fluctuations of population abundance of stoat.

Data on stoat furs acquisitions in Komi Republic (Russia) for the period of 60 years (1920-80) showed 3-4 years fluctuations of population abundance (Gornostay, 2012), while in Karelia 4-7 years periodicity was identified (Outlines, 2014). All this sources stated that population abundance of stoat is cyclical, but the lengths of cycles are different. Moreover these studies do not pay attention to the significance of cycles for populations. We suggest that population cycles are necessary for coordination with numerous cyclical influences of environment, among which are climate influences. And that is more important they are necessary for the adjustment to fluctuations of prey base.

\footnotetext{
${ }^{1}$ Agafonov G. Research contributor. Institute of Natural Resources, Ecology and Cryology, SB RAS, Chita,

2 Erdakov L., DPhil, Professor Novosibirsk State Pedagogical University; Institute of Taxonomy and Ecology of Animals SB RAS

Corresponding author> Agafonov G. Research contributor: mosgenatik@yandex.ru
} 
Our study is based on the assumption that stoat population abundance is cyclical. The main goal of the research is to determine this cyclicality of stoat in Transbaikal region. To achieve this goal we aimed to clarify the following: is the abundance of stoat population cyclical; determine rate and quantity of cycles in each district; and reveal similarity and dissimilarity of the population dynamics between different districts of Transbaikal region.

In addition we compare, by rate and power spectra of periodical components, spectra of population dynamics from different areas assuming that the dissimilarities were the causes of inconsistency of information on stoat cycles in existing literature.

\section{Material and methods}

We used data on stoat furs acquisitions (20,143 items) gathered in 14 districts of Transbaikal region for the period of 19 years (1971-89). We assume that this data generally reflects long-term course of population abundance of stoat in the hunting areas.

The area of Transbaikal region is 431.5 thousand square kilometers (maximal extension in the longitudinal direction is about 1,000 kilometers, in latitudinal - around 800 kilometers). Transbaikal region is situated in the middle of the Eurasia. It embraces significant part of Central Asian world watershed divide that separates the basins of Pacific and Arctic oceans. Here originate the biggest rivers of the Earth: Amur River, Lena River, and Yenisei River. The Western part of the Transbaikal region belongs to the basin of Lake Baikal World Natural Heritage site.

The climate is severely continental with low level of atmospheric precipitation, long harsh winters, and relatively warm (sometimes hot) summers, which are dry in their first half and wet in the second one, with significant diurnal and annual fluctuations of the atmospheric temperature (up to $94^{\circ} \mathrm{C}$ ). Average annual atmospheric temperature is below $0^{\circ} \mathrm{C}$ (Chita city $-2.7^{\circ} \mathrm{C}$ ). Frost-free season ranges from 80 to 140 days. Atmospheric precipitations are between 400 and 800 millimeters annually. In the winter atmospheric precipitation is equal to around $5-10 \%$, in summer $-90-95 \%$.

Taiga zone occupies south-western, north-eastern, and northern parts of the region. The main forest forming species are larch (Larix daurica), Scotch pine (Pinus silvestris), and Siberian cedar (Pinus sibirica). In taiga numerous rivers and streams with narrow and wide valleys, stone fields, and burnt areas are the main habitats of a stoat.

Typically, data distribution on the time scale influences analyses. It allows only approximate analysis of causes for population abundance changes, regularities of its course (for forecast), and detection of presence of latent components. Therefore it is difficult to compare long-term population dynamics using chronograms of furs acquisitions. Scholars typically use correlation analysis, but even high correlation indexes do not allow identifying causes and fail to show causal connections between processes. However data could be presented on the frequency scale rather than on the time scale. In this case we will be able to identify quantity and lengths of periodical components of the process under consideration. Presence of such kind of rhythms bears additional biological information and could clarify both course of population dynamics and several endogenous and exogenous causes.

We used the method of data processing designed to count harmonical components, their rate and power in long-term dynamics of furs acquisition.

We used time-series analysis for detection of latent fluctuations (Jenkins \& Watts, 1971). Spectral analysis software was used for calculations (Telepnev \& Erdakov, 2014). Data was analyzed with Welch method (Marpl, 1990). All calculations were made via free system of mathematical calculations (GNU Octave, 2014). Particularly we used the package Octave-Forge for the assessment of spectral density by Welch method (Erdakov, 2011). Statistical analysis was made with PAST.exe software package.

We are using the following terminology in the paper.

Harmonic component (constituent element) - a change repeating in one and the same time, which takes place in animate and inanimate nature.

Spectrum of rhythms - characteristic of the function, which is presented in the form of dependence of powers of harmonic components (constituent elements) from their frequencies.

Spectral density - number of spectra of the particular frequencies for the chronogram (weight of each spectrum). 
Frequencies - number of cycles per unit time.

\section{Results and discussion}

\section{a) Distinctions of abundance fluctuations}

To explore the population cyclicality which is indicative for stoat in Transbaikal region we used data acquired for Sretenskiy district as one of the central districts in the region. Average long-term rate of furs acquisition for the period of observations was $\mathrm{M} \pm \mathrm{m}=7.58 \pm 1.21$ (pcs.) $\sigma=5.29$. Course of population abundance is presented on the chronogram as highly deformed curve with the peaks of every 2, 3, 4, and more years (Figure 1).

Range of furs acquisition varies from maximum in 1971 (21 pcs) to minimum in 1982 (1 pcs). Basing on this chronogram we could assume the existence of approximately 20 years cycle in dynamics of stoat. Some of these cyclicalities were mentioned in the above cited references but we would like to more precisely identify cycles, superposition of which indeed presents chronogram depicted in Figure 1.

For exploration of values of latent periodical components in long-term course of acquisitions we constructed spectrum of rhythms which are implicated in chronogram (Figure 2). There are three cycles in total. Notably the most powerful one is low-frequency cycle, which we presupposed on the chronogram. Powers of our series are insufficient for the exact determination of the period of such rate. Therefore on the spectrum we got relatively smooth peak with broad base.

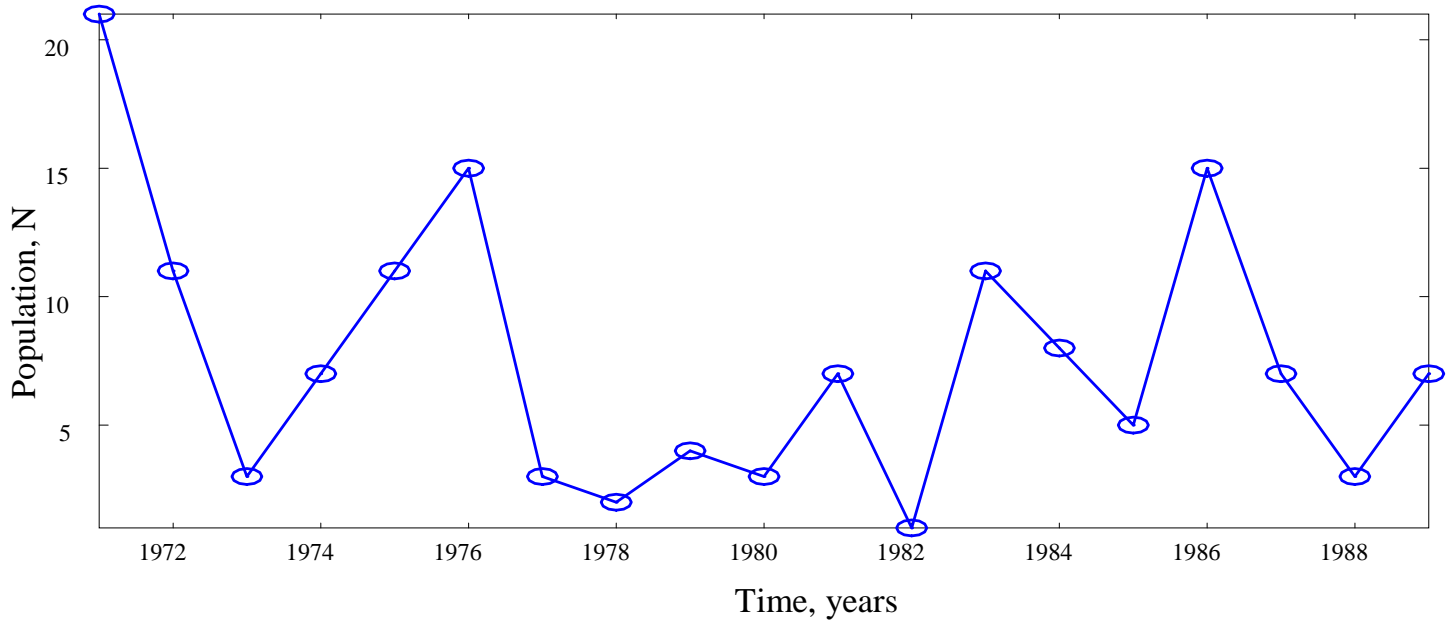

Figure 1. Chronogram of abundance dynamics of stoat based on the acquisition of furs in Sretenskiy district.

The most evident cycle, approximately 2 years, is presented by second, in rate, peak with regular exponential shape with very narrow base. Moreover there is approximately 4 years cycle with wellexpressed peak of regular form and quite narrow base on the spectrum. These three cyclicalities, overlapping each other, create distinct picture of dynamics. We have not found references to approximately 20 years fluctuations of population abundance of stoat, but acquired spectrum does not also show neither 3 years nor 6 and 7 years cycles described for the species. 


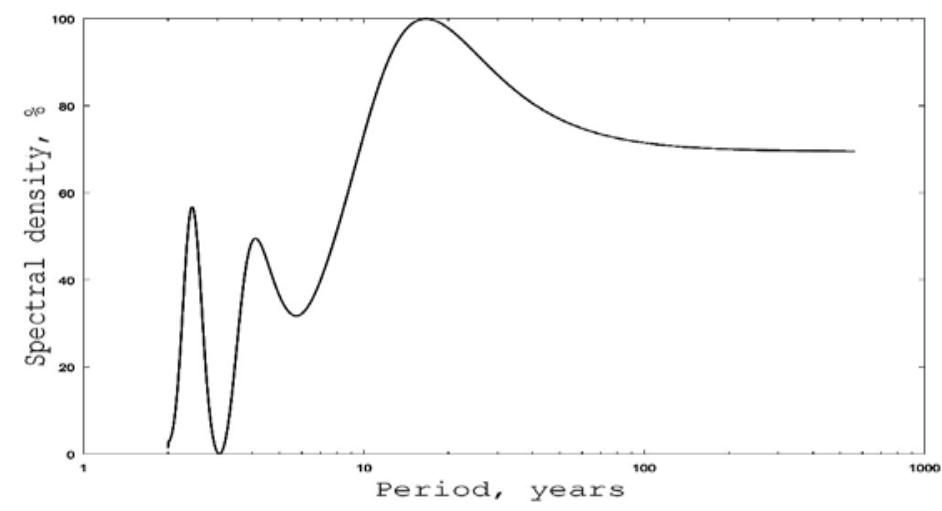

Figure 2. Spectrum of rhythms which is indicative for population dynamics of stoat based on data of furs acquisitions in Sretenskiy district

Table 1. Interrelation of rate and power of periodical components of long-term population dynamics of stoat

\begin{tabular}{|l|l|l|l|}
\hline District & $16-18$ & $3.5-5$ & $2-2.8$ \\
\hline Sretenskiy & & & \\
\hline & 16.47 & 4.12 & 2.43 \\
& 1.08 & 0.53 & 0.61 \\
\hline
\end{tabular}

Note: upper character: upper figure - period, years, lower figure- power (spectral density units)

We calculated values for periods and their interrelation in power to clarify the pattern of cyclicality (Table 1). As expected, the most powerful is low-frequency cycle, but its period is significantly shorter than 20 years. Second by power is approximately 2.5 years cycle. And the last is 4 years cycle. Likely the population abundance cyclicality could vary in different regions, and then the cycles which were not identified in Sretenskiy district of Transbaikal region could appear. Data we have allow us to check this presupposition.

\section{b) territorial distinctions in population abundance cyclicality of stoat}

To identify distinctions in cyclicality we built spectra of rhythms of acquisitions of stoat furs for 14 districts of Transbaikal region. Notwithstanding the distinctions depictions of spectra could be grouped by its formal resemblance in three groups. First one includes districts where low-frequency cycle is prevalent, while all others are insignificant in power (Figure 3). 

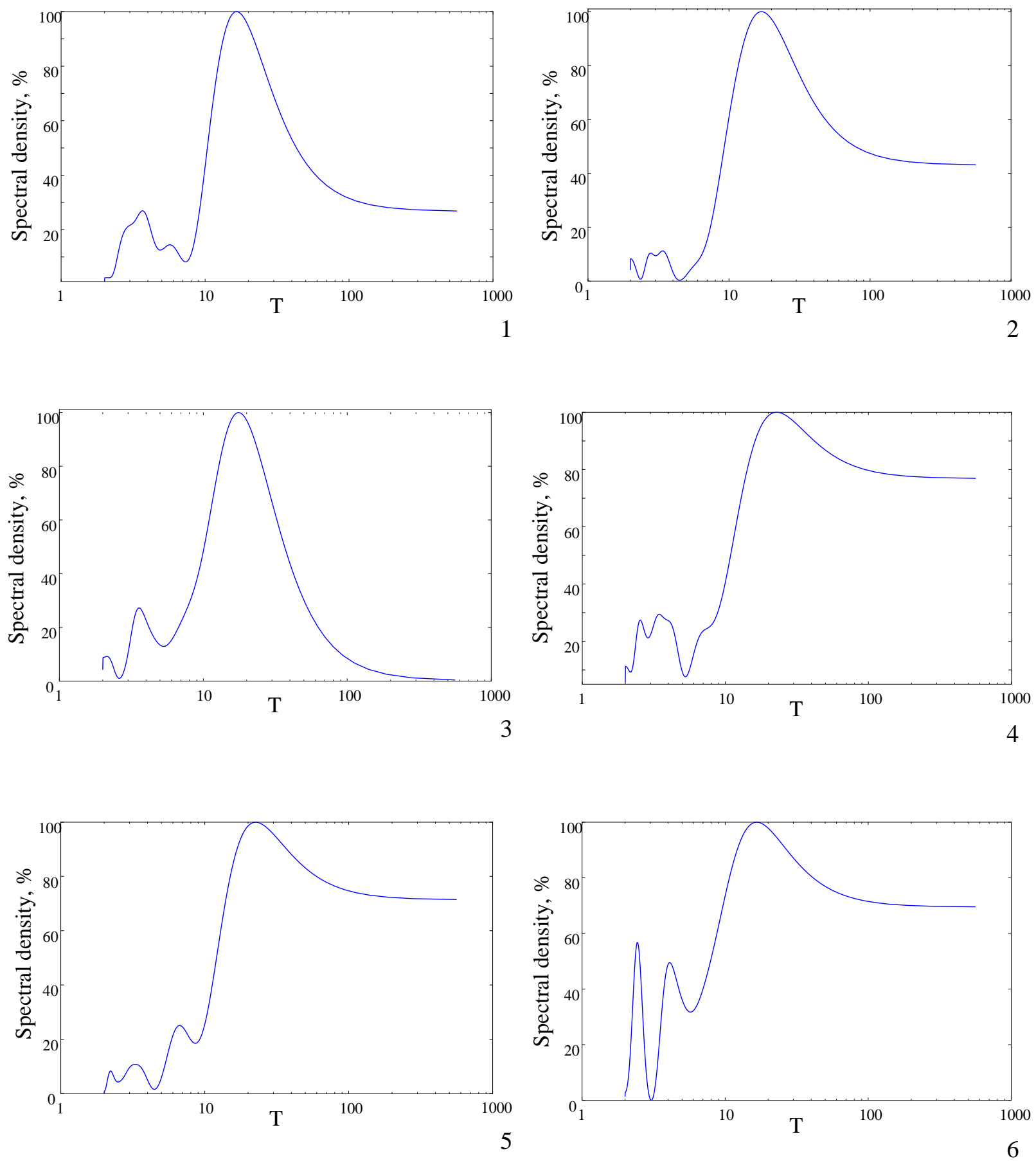

Figure 3. First group (see Table 2): Spectra of rhythms of furs acquisition in which one harmonic component is totally prevalent by power. 1. Petrovsk-Zabaykalskiy, 2. Kalarskiy, 3. Akshinskiy, 4. Tungiro-Olyokminskiy, 5. Chernyshevskiy, 6. Sretenskiy.

Second group includes districts where only high-frequency cycles were identified, while low-frequency ones were totally absent (Figure 4). Sretenskiy district depending on the type of spectrum ofrhythms of acquisitions could be acknowledged as transitional from the first group to the second one. Finally, third group includes districts which have cyclicalities both in high- and low-frequency bands; although high- 
frequency harmonical components are prevalent by power. Their spectra had transitional character, i.e. had significant by power both high- and low-frequency periodicities.
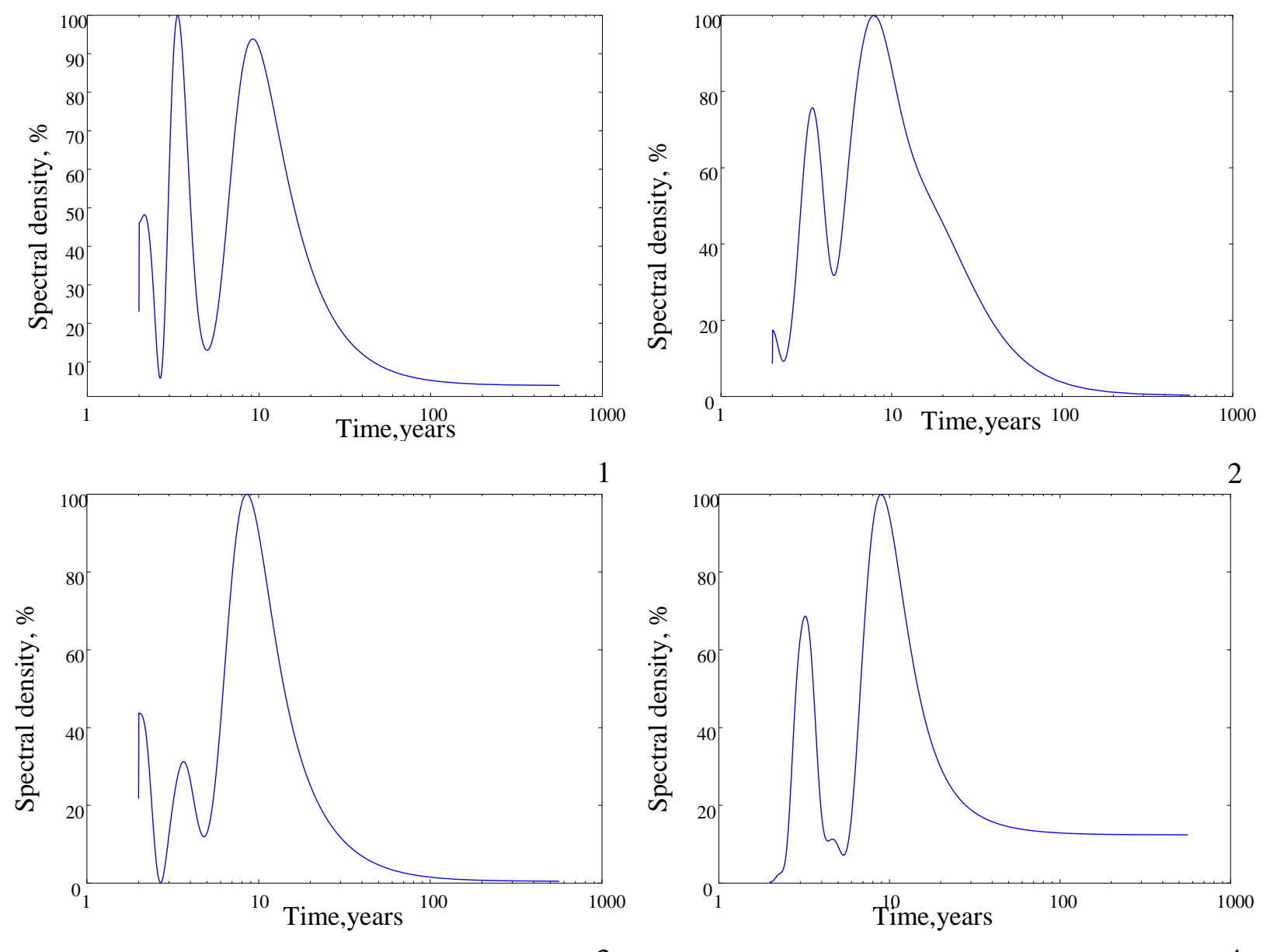

Figure 4. Second group (see Table 2): Spectra of rhythms of furs acquisitions which have not lowfrequency rhythms. 1. Khilokskiy, 2. Ulyotovskiy, 3. Chitinskiy, 4. Kyrinskiy.

To clarify values of periods on spectra as well as to clarify interrelations of power of harmonic components we unified parameters of all calculated cycles into one table (Table 2).

Currently, using the data from the table above we could get a clear picture about long-term cycles which are typical for stoat. Population abundance fluctuations of 19-22 years are common for stoat in Transbaikal region. These cycles appear in many districts but for some districts they are the most powerful in the course of abundance dynamics. Close to them are 16-18 years cycles that are also indicative for some districts. And if they appear in such districts they always dominate the spectrum by power. In relatively small number of districts there are approximately 10 years cycles of population abundance (7-12 years) and in such districts they appear at the lowest frequency. In small number of districts there are approximately 6 years cycles of population abundance. 
Table 2. Periodical components of population dynamics of stoat in different districts of Transbaikal region

\begin{tabular}{|c|c|c|c|c|c|c|}
\hline District & $19-26$ & $12-18$ & $7-12$ & $5-6$ & $3-4.8$ & $2-2.8$ \\
\hline \multicolumn{7}{|l|}{1 group } \\
\hline Akshinskiy & & $\begin{array}{l}17.50 \\
10\end{array}$ & & & $\begin{array}{l}3.58 \\
2.83\end{array}$ & $\begin{array}{l}2.14 \\
0.95\end{array}$ \\
\hline Kalarskiy & & $\begin{array}{l}16.96 \\
886.66\end{array}$ & & & $\begin{array}{l}3.39 \\
99.37\end{array}$ & $\begin{array}{l}2.77 \\
91.97\end{array}$ \\
\hline $\begin{array}{l}\text { Petrovsk- } \\
\text { Zabaykalskiy }\end{array}$ & & $\begin{array}{l}16.47 \\
1.51\end{array}$ & & $\begin{array}{l}5.71 \\
0.21\end{array}$ & $\begin{array}{l}3.68 \\
0.40\end{array}$ & $\begin{array}{l}2.67 \\
0.26\end{array}$ \\
\hline $\begin{array}{l}\text { Tungiro- } \\
\text { Olyokminskiy }\end{array}$ & $\begin{array}{l}22.40 \\
20.45\end{array}$ & & & & $\begin{array}{l}3.45 \\
6.01\end{array}$ & $\begin{array}{l}2.54 \\
5.59\end{array}$ \\
\hline Chernyshevskiy & $\begin{array}{l}22.40 \\
3.22\end{array}$ & & & & $\begin{array}{l}3.29 \\
0.34\end{array}$ & $\begin{array}{l}2.21 \\
0.26\end{array}$ \\
\hline Sretenskiy & & $\begin{array}{l}16.47 \\
1.08\end{array}$ & & & $\begin{array}{l}4.12 \\
0.53\end{array}$ & $\begin{array}{l}2.43 \\
0.61\end{array}$ \\
\hline \multicolumn{7}{|l|}{2 group } \\
\hline Khilokskiy & & & $\begin{array}{l}9.18 \\
30.67\end{array}$ & & $\begin{array}{l}3.35 \\
32.68\end{array}$ & $\begin{array}{l}2.15 \\
15.75\end{array}$ \\
\hline Ulyotovskiy & & & $\begin{array}{l}7.88 \\
18.93\end{array}$ & & $\begin{array}{l}3.43 \\
14.34\end{array}$ & \\
\hline Chitinskiy & & & $\begin{array}{l}8.48 \\
13.03\end{array}$ & & $\begin{array}{l}3.66 \\
4.07\end{array}$ & $\begin{array}{l}2.01 \\
5.69\end{array}$ \\
\hline Kyrinskiy & & & $\begin{array}{l}8.89 \\
63.88\end{array}$ & & $\begin{array}{l}3.21 \\
43.86 \\
4.62 \\
7.23\end{array}$ & \\
\hline \multicolumn{7}{|l|}{3 group } \\
\hline Mogochinskiy & & $\begin{array}{l}12.44 \\
39.91\end{array}$ & & & $\begin{array}{l}4.34 \\
40.47\end{array}$ & $\begin{array}{l}2.01 \\
73.07\end{array}$ \\
\hline Baleyskiy & $\begin{array}{l}20.74 \\
2.28\end{array}$ & & & $\begin{array}{l}6.08 \\
4.13\end{array}$ & $\begin{array}{l}3.04 \\
1.38\end{array}$ & \\
\hline Kransochikoyskiy & $\begin{array}{l}19.31 \\
22.92\end{array}$ & & & $\begin{array}{l}6.02 \\
24.77\end{array}$ & $\begin{array}{l}3.43 \\
98.25\end{array}$ & $\begin{array}{l}2.12 \\
3.42\end{array}$ \\
\hline Tungo-Kochenskiy & $\begin{array}{l}23.33 \\
218.10\end{array}$ & & & $\begin{array}{l}5.83 \\
76.86\end{array}$ & $\begin{array}{l}3.71 \\
398.87\end{array}$ & \\
\hline
\end{tabular}

Note: upper character - period, years, lower - power (spectral density units)

With respect to approximately 4 years cyclicality, this cyclicality is described in most studies devoted to assessment of dynamics of stoat which are based both on records data and analysis of furs acquisition. Periodicity of dynamics which are close to 4 years is typical for all districts of Transbaikal regionwhich are under consideration in this paper (Table 2). Short approximately 2 years cycles turned out to be almost of the same regularity for population dynamics of stoat. 
Therefore, stoat population abundance is changed cyclically; the most typical fluctuations for stoat are high-frequency fluctuations ( 3 and 4 years).

Most likely they are used by stoat population for adjustments to fluctuations of its main prey. It could be field vole. Typically there could be 5-8 species of these copious animals on the same territory. Their basic population cyclicality is 3-4 years. This cyclicality is distinct for different population in the range. Thus field voles avoid close competitive relations between sympatric populations. The same characteristic of cyclicality allows maintaining of permanently high population abundance for all of these groups of species (Erdakov, 2011). Stoat population adjusts to fluctuations of its preys. Therefore it is the best for the population to have powerful harmonic components in necessary band of frequencies rather than one. This provides predator with the opportunity to annually synchronize its fluctuations with cycles of the type of prey which is dominating in the recent year.

In some districts stoat populations have explicit 7-9 years rhythms, provided that on the spectrum it dominates by power (Table 2). It is known that exactly at this band of frequencies the most powerful population cycles of such large rodents, as common hamster and water vole, appear (Erdakov, 2011). Likely this periodicity of predator population abundance is also connected to the cyclicality of its preys.

There are other cycles of stoat in many districts of Transbaikal region. Part of them was described in literature earlier, as being visually determined based on long-term population abundance changes, on others - low-frequency - we failed to find any information. These long-term cycles most probably are used for coordination with climate cycles, such as 22 years cycle of precipitation (Drozdov \& Grigoryeva, 1971), approximately 15 years temperature cycle (Taranyuk, 2000), or approximately 10 years cycle of winters' severity (Bukharitsin \& Andreyev, 2006).

Most probably, spectrum of 6-8 explicit periodicities is typical for this species, but in every region only part of them is expressed. Full spectrum of rhythms of this species, probably, could be identified on the longer series of observations.

\section{Conclusion}

The study of population dynamics of stoat which is based on data on furs acquisitions gathered in different districts of Transbaikalia allowed to identify that shaped curves of acquisition dynamics are superposition of several cycles which are different by amplitude and power.

Through the time-series analysis, which is graphically represented as chronograms of course of population abundance in different districts, we built distinct patterns of spectra of rhythms and conducted visual comparison of these spectra across different regions. All districts were divided depending on the form of spectra of abundance cycles. Low-frequency rhythms (12-22 years) were prevalent by power in first group. In the second group these rhythms were totally absent. Third group of spectrum was of transitional nature, there were rhythms on all band of frequencies distinct for this species. Highfrequency rhythms were typical for the most part of spectra, but approximately 4 years cycles were marked for all cycles without any exceptions.

For each district we calculated values of periods of cycles and powers for each of period. Part of them was already described in literature as distinct for population abundance changes of stoat. However we gave description of low-frequency rhythms (16-26 years) for the first time.

\section{Acknowledgment}

The study was performed with the support of the project of SB RAS No. IX. 88. 1. 6.

\section{References}

1. Bukharitsin P.I., Andreyev A.N. Rhythms of solar activity and expected extreme climate events in North-Caspian region for the period of 2007-2011. Extreme hydrogeological events in Aral-Caspian region. Proceedings of international scientific conference. Moscow, October 19-20, 2006. pp. 137-143.

2. Drozdov O.V., Grigoryeva A.S. Long-term cyclical fluctuations of atmospheric precipitations on the territory of USSR. - Leningrad: Gidrometeoizdat. 1971. - 316 p.

3. Encyclopedia of wild animals of Urals http://krec-in.ru/gornostai.html- : accessed: July 21, 2014

4. Erdakov Lev. Biological rhythms: bion, population, association. Cyclisity in living systems. LAP LAMBERT Academic Publishing (01.07.2011) GmbH \&Co.KG. 152 p. 
5. Formozov A. N. Variation of game animals' abundance. Moscow-Leningrad:KOIZ,1935. 108 p.

6. GNU Octave. http://www.gnu.org/software/octave/- accessed: July 23, 2014

7. Gornostay. RAS, Nauka, Fauna of European North, 2012 http://abc24.info/living_world/zoologiya/ 1039gornostay.html- accessed: July 30, 2014

8. Jenkins G., Watts D. Spectral analysis and its applications, Moscow, Mir, 1971, 317 p.

9. Kolosov A. M., Lavrov N. P., Naumov S. P. Biology of game animals of USSR. Moscow.: High school, 1979. 416 p.

10. Marpl Jr. S. L. Digital spectral analysis and its applications, 1990. Publishing house Mir, ISBN 5-03-001191-9.

11. Outlines of ecology of animal species for hunting in Karelia http://welcome-karelia.ru/ocherki-ekologii-vidov-zvereydlya-ochoti-v-karelii/gornostay-mustela-erminea-l)- accessed: August 2, 2014

12. Semenov V.B. About regularities of short-period fluctuations of stoat abundance on the north of the European part of USSR and their usage for forecasting of stoat furs acquisitions. - in Biological foundations and experience of forecasting of abundance changes of game animals. Kirov: publishing house of All-Union Research Institute for Hunting Husbandry and Livestock Breeding, 1976, pp. 234-235

13. Taranyuk M.I. Studying of climate cyclicity and monitoring of atmospheric processes on the territory of south-east of Western Siberia. Synopsis of a thesis of candidate of sciences in geography TSU. Tomsk, 2000.

14. Tavrovskiy V.A., Egorov O.V., Krivosheyev V.G. et all. Mammals of Yakutia. Moscow, Nauka, 1971, 640 p.

15. Telepnev V.G., Erdakov L.N. Description of population cycles of wood grouse (Tetrao urogallus L., 1758) through long-term monitoring. Contemporary Problems of Ecology. September 2014. Volume 7, issue 5, pp. 530-536.

Received: 29.03.2015.

Accepted: 19.09.2015.

Agafonov G. \& Erdakov L. (2015). Population fluctuation of stoat (Mustela erminea L., 1758) in Transbaikal region (Russia), Balkan Journal of Wildlife Research, 2(2), pp. 9-17. 